\title{
O papel da mídia na construção do discurso de "pacificação" no Rio de Janeiro ${ }^{1}$
}

\author{
The media's role in building the speech "pacification" in Rio de Janeiro \\ El papel de los medios de comunicación en la construcción del discurso de \\ "pacificación" en Río de Janeiro
}

Vitor Monteiro de Castro $^{2}$

\begin{abstract}
Resumo
O artigo procura demonstrar como a mídia é um instrumento de hegemonia, levando em conta a noção de "guerra" e "pacificação" utilizada pelos meios de comunicação para definir as ações da política de segurança pública do Rio de Janeiro. Para isso fazemos um breve levantamento das políticas de segurança adotadas e de como as favelas e espaços populares vêm sendo retratados pela mídia. Mais especificamente em dois momentos, até 2008, antes da instalação da primeira Unidade de Polícia Pacificadora (UPP) e após esse momento, quando a noção de "guerra" perde espaço para o discurso de "pacificação" pelos meios oficiais, e a mídia passa a seguir essa mesma cartilha, sem qualquer criticidade. Para isso discutimos a questão da hegemonia e suas formas de preservação e legitimação do poder, apresentando trechos de editorias, matérias e reportagens do jornal O Globo.
\end{abstract}

Palavras-chave: Mídia. Favela. Pacificação. Hegemonia.

\begin{abstract}
The article shows how the media is a hegemonic instrument, taking into account the notion of "war" and "pacification" used by the media to define the actions of public security policy in Rio de Janeiro. For it makes a brief survey of the adopted security policies and how favelas and popular spaces have been portrayed by the media. More specifically in two stages, by 2008 , before the installation of the first Police Pacification Unit (UPP in portuguese) and after that moment, when the notion of "war" loses space for discourse of "pacification" by the official media, and the media passes after that as well without any criticality. For this we discussed the question of hegemony and its forms of preservation and legitimation of power, featuring excerpts from editorials and reports O Globo newspaper.
\end{abstract}

Keywords: Media . Favela . Pacification . Hegemony.

\section{Resumen}

El artículo muestra cómo los medios de comunicación es un instrumento hegemónico, teniendo en cuenta la noción de "guerra" y "pacificación" utilizado por los medios de comunicación para definir las acciones de la política de seguridad pública en Río de Janeiro. Para ello hacemos una breve encuesta de las políticas de seguridad adoptadas y cómo favelas y espacios populares se han retratado por los medios. Más específicamente en dos etapas, para el año 2008, antes de la instalación de la

\footnotetext{
${ }^{1}$ Este trabalho foi desenvolvido dentro do Projeto de Pesquisa Rupturas Metodológicas para uma leitura crítica da Mídia entre os Programas de Pós-Graduação da UFG e UFRJ, que integra a ação transversal no 06/2011 - Casadinho/Procad.

${ }^{2}$ Doutorando do programa de Pós-Graduação da Escola de Comunicação da Universidade Federal do Rio de Janeiro (UFRJ). Brasil, Rio de Janeiro, Rio de Janeiro. E-mail: vitormonteirodecastro@gmail.com.
}

Comun. \& Inf., Goiânia, GO, v. 18, n. 02, p. 198-216, jul./dez. 2015 
primera Unidad de Policía Pacificadora (UPP) y después de ese momento, cuando la noción de "guerra" pierde espacio para el discurso de la "pacificación" de los medios de comunicación oficiales y los medios de comunicación comienza a seguir la misma línea sin ningún tipo de criticidad. Para ello hemos discutido la cuestión de la hegemonía y de sus formas de preservación y legitimación del poder, con extractos de editoriales y informes del periódico O Globo.

Palabras clave: Medios de Comunicación. Favela. Pacificación. Hegemonía.

\section{INTRODUÇÃ̃o}

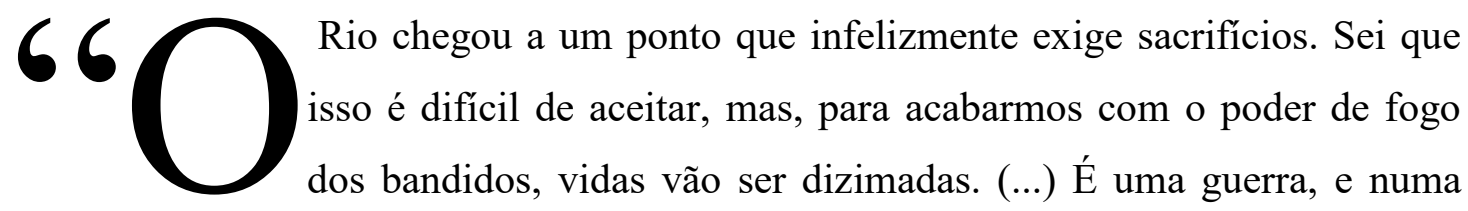
guerra há feridos e mortos”. Essa declaração foi dita pelo secretário de Segurança Pública do Rio de Janeiro, José Mariano Beltrame, em entrevista à revista Veja, em 2007, sobre as ações policiais em favelas cariocas.

Cinco anos depois, em 2012, o mesmo secretário de Segurança, em entrevista sobre o filme "5x Pacificação", afirma que "não será a polícia ou um policial com um fuzil em uma escadaria de uma favela que vai resolver o problema [da violência] (...) [o filme] mostra exatamente que segurança pública é um conjunto de coisas".

O discurso, que em 2007 pregava a "guerra" ao tráfico como solução para a violência no Rio de Janeiro, cinco anos depois apresenta uma visão completamente oposta. Se antes o tiroteio era lugar-comum e os moradores desses espaços eram tratados como vítimas de guerra, a partir do final de 2008 a política de segurança muda completamente o viés do discurso - com a nova lógica de "pacificação" - e altera com alguma timidez as ações de segurança pública em favelas.

O discurso midiático acompanha imediatamente a nova perspectiva apresentada pela política de segurança carioca. Como afirma Gramsci, a imprensa é a parte mais dinâmica da estrutura ideológica - embora não seja a única - que influi sobre a opinião pública. Isso, conclui o pensador italiano, "requer um complexo trabalho ideológico, cuja primeira condição é o exato conhecimento do campo a ser esvaziado de seu elemento de massa humana" (BELTRAME, 1999, v. 2, p.79).

A partir das concepções de Maquiavel, que busca identificar como consolidar o domínio para que o Estado seja duradouro através da figura do príncipe - equilibrando forças entre interesses e lutas, rompendo com a dimensão ética, pregando o pragmatismo -, e da teoria gramsciana de moderno príncipe - que organiza uma reforma intelectual e moral 
através do partido -, que apresentaremos a mídia como um dos principais instrumentos de manutenção da hegemonia e que elabora, difunde e legitima determinadas visões de mundo, naturalizando as ações da política de segurança pública na cidade do Rio de Janeiro. Ampliando esta dimensão, trabalhamos com o conceito de príncipe eletrônico, cunhada pelo brasileiro Octávio Ianni, que trabalha com a ideia de que a mídia ultrapassa as atividades tanto do príncipe quanto do moderno príncipe, já que permeia todos os níveis da sociedade.

Nosso entendimento tem fundamento também no conceito de hegemonia de Gramsci, que a caracteriza como a liderança ideológica e cultural de uma classe sobre as outras. Neste sentido, a mídia hegemônica não representa de forma plural os interesses de toda a sociedade, já que se limita a interesses de classe, e tem uma preocupação em atender a suas demandas imediatas, no caso, ligada às classes média e alta, deixando de lado interesses das classes econômicas mais baixas. $\mathrm{O}$ espaço de persuasão que antes pertencia aos intelectuais passou a ser dividido, e muitas vezes ocupado, por outras esferas de mediação, principalmente pela mídia. Como afirma Dênis de Moraes,

os meios de difusão agem como uma espécie de intelectual orgânico que define e interfere na conformação dos imaginários sociais e dos valores, além de formarem seus próprios intelectuais (autores, diretores, estrategistas), em função de seus alvos mercadológicos e visões ideológicas (JB ON LINE, 2004).

Este artigo pretende demonstrar como a mídia se transformou num instrumento de hegemonia. Nesse estudo de caso específico, a mídia altera seu discurso de acordo com os interesses da política de segurança, deixando de lado qualquer discussão mais ampliada sobre o contexto dessa política. O artigo faz um breve levantamento das políticas de segurança adotadas no Rio de Janeiro nas últimas décadas e a forma como as favelas e espaços populares vêm sendo retratados ao longo do século XX pela mídia. Na sequência discutimos a questão da hegemonia e suas formas de preservação e legitimação do poder dominante, apresentando trechos de editoriais e reportagens do jornal O Globo, jornal de maior circulação no Rio de Janeiro, para avaliar os discursos apresentados nos dois momentos estudados: até o final de 2008, em que a política de segurança se baseava na lógica do confronto, de "guerra" às drogas; e a partir da instalação da primeira Unidade de Polícia Pacificadora (UPP) no Morro Santa Marta, em Botafogo, na zona sul do Rio de Janeiro, quando a lógica de "guerra" dá lugar ao conceito de "pacificação", de uma nova política de segurança que seria baseada não mais no confronto, mas na ocupação dos espaços pela polícia - até então "dominados" pelo tráfico - e também com ações sociais e de desenvolvimento. Nossa hipótese para a 
mudança desse discurso leva em consideração a necessidade de apresentar uma cidade do Rio de Janeiro mais segura e tranquila por conta dos megaeventos que a cidade tem sido sede, como a Copa das Confederações de Futebol, Copa do Mundo de Futebol e principalmente os Jogos Olímpicos de 2016.

\section{FAVELAS CARIOCAS E SUA REPRESENTAÇÃO NA MÍDIA}

Já no início do século XX podemos observar como o tratamento dispensado às favelas pela mídia hegemônica no Brasil, em especial na cidade do Rio de Janeiro, se deu de forma preconceituosa. Os moradores de favelas eram considerados pela imprensa a "classe perigosa", e a favela era definida como um verdadeiro "inferno social", "lepra da estética" e um espaço que deveria ser eliminado (VALLADARES, 2008). Essa caracterização se mantém durante todo o século XX e ganha força a partir da década de 1980, com a implantação de uma política de segurança pública. Nesse momento as favelas passam a ser tratadas pela mídia como territórios inimigos em uma guerra contra o tráfico de drogas, uma visão que acabava por legitimar o confronto.

Como explica Cecília Coimbra, essa concepção foi influenciada pela Doutrina de Segurança Nacional, enraizada no cotidiano a partir da ditadura militar. Para Coimbra (2000), o uso da Doutrina de Segurança Nacional contra "inimigos internos" torna possível a crescente criminalização dos pobres, em especial os moradores de favelas, que são reconhecidos como as "classes perigosas". É uma espécie de retomada do discurso higienista do final do século XIX e início do XX, que identificava a população pobre como vetor de doenças e degenerados (COIMBRA, 2000, p. 18).

A partir de 1980, em nome do combate ao tráfico de drogas, políticas de enfrentamento tornam rotineiro o uso da letalidade pelas forças policiais como indicador de eficiência. É nesse ambiente que surge a dimensão da "guerra", em que há um inimigo que é identificado por critérios geográficos, sociais e raciais, impondo, com a colaboração decisiva da mídia, a generalização entre pobreza, raça e crime. Por exemplo, entre 2002 e 2010 morreram 125,6\% mais jovens (entre 15 e 24 anos) negros do que brancos (WAISELFISZ, 2012, p.10), e com uma tendência de queda do número absoluto de homicídios na população branca e de aumento nos números da população negra.

Essa concepção de segurança foi constante em diversos governos do Rio de Janeiro. Em 1995, durante o governo Marcelo Alencar, foi implantado pelo então secretário de 
Segurança Newton Cerqueira a "premiação faroeste" (1995-1997), uma gratificação oferecida a policiais militares que praticassem atos considerados de bravura pelo comando da corporação. Esta premiação promoveu o acobertamento e fortaleceu os crimes cometidos por agentes do Estado (COIMBRA, 2000, p. 239)

Em 2003, durante o governo de Benedita da Silva, o então secretário de Segurança Pública Josias Quintal implementou a "Operação Rio Seguro". Na ocasião o secretário disse ao jornal O Globo de 27 de fevereiro que "se tiver que ter conflito, que tenha. E, se alguém tiver que morrer, que morra. Mas nós vamos partir pra dentro" (p. 15). No governo seguinte, de Rosinha Garotinho, o então secretário de Segurança Anthony Garotinho, em entrevista ao mesmo O Globo de 11 de maio de 2006 (p. 16), comemorou a morte de 100 pessoas (supostos bandidos) em apenas 15 dias no cargo. Em 2007, com a eleição do governador Sérgio Cabral, a política de enfrentamento ganha ainda mais força e intensifica o uso do Caveirão - veículo militar de combate utilizado pelas Polícias Militar e Civil do Rio de Janeiro.

Essa representação de um conflito social como guerra implica acionar um repertório simbólico em que lados opostos são inimigos, de que o extermínio é uma estratégia para a vitória e que inocentes mortos ou feridos são consequências dessa guerra. É necessário pensar na desconstrução tanto do discurso da guerra como no da pacificação. Não há uma guerra quando temos de um lado um aparato estatal coercitivo e, de outro, traficantes de drogas armados pela corrupção do próprio Estado. Uma guerra acontece entre dois exércitos. O tráfico de drogas ilegais não está em guerra contra a polícia. Nesse sentido, também não haveria uma pacificação, mas uma mudança na forma como o Estado atua nas favelas. A naturalização dessa lógica de guerra cria no imaginário coletivo a sensação de que estamos no pior dos mundos, e que a morte de moradores e criminosos faz parte desse processo. $\mathrm{O}$ pesquisador Michel Misse (2006) explica que esse imaginário tem apelo comercial e alimenta a insegurança e a sensação de medo,

produzindo esse sujeito difuso da 'violência urbana', com suas metáforas de guerra, suas vítimas intermináveis, suas assombrosas estatísticas de mortos e feridos. A mídia não descreve apenas o que chama de violência, ela também participa da sua construção, é também um dos atores desse drama social (MISSE, 2006, p. 25-26).

Como resultado dessa estratégia de guerra, "megaoperações" policiais passam a ser realizadas em favelas com um aumento significativo dos autos de resistência - termo utilizado para os casos de morte durante suposto confronto com a polícia e resistência à prisão. Para se ter uma ideia do crescimento deste índice, ao longo de uma década os autos de resistência 
aumentaram mais de 440\% - de 300 vítimas em 1997 para 1330 em 2007, segundo dados do Instituto de Segurança Pública do Estado do Rio de Janeiro (ISP-RJ).

A partir de dezembro de 2008 uma nova política de segurança pública, que não prega mais a lógica do confronto, da "guerra às drogas", aponta no horizonte do Rio de Janeiro, com a instalação da primeira Unidade de Polícia Pacificadora (UPP), na favela Santa Marta, em Botafogo, Zona Sul da capital. É nesse período também que o Brasil vence a eleição da Federação Internacional de Futebol Associado (Fifa) para sediar a Copa do Mundo de Futebol (em 30 de outubro de 2007) e que a cidade do Rio de Janeiro é eleita uma das cidades-sede da Copa (em 31 de maio de 2009). Ainda em 2009, no dia 2 de outubro, o Rio de Janeiro vence a disputa para sediar os Jogos Olímpicos de 2016. Foram anúncios que abriram caminhos para grandes investimentos da iniciativa privada e da necessidade de aumentar a sensação de segurança. Ou como apontou Misse, alterar no imaginário a sensação de insegurança e medo propagada ao longo das últimas décadas. Surge então a lógica da "pacificação", em detrimento ao discurso de "guerra".

Para atingir esse objetivo, de alterar a imagem construída ao longo de décadas de uma cidade partida e de intenso conflito para uma cidade "pacificada" e que caminha em direção à paz, além da publicidade oficial, a mídia teve papel fundamental. Historicamente, a mídia se utilizou muito pouco de sua capacidade de pautar um debate público consistente sobre segurança pública, com tratamento superficial sobre o tema. Essa sua superficialidade nunca motivou ações do Estado mais eficazes e abrangentes. Ainda quando se altera o discurso estatal sobre a política de segurança, a mídia não tem papel reflexivo sobre essa mudança, mas simplesmente passa a retransmitir esse novo discurso oficial.

Se antes havia uma falta de opiniões divergentes nas matérias jornalísticas que fossem contra o senso comum do discurso de "guerra", após a instalação das primeiras UPPs passa a ser quase impensável ver especialistas promovendo o combate via confronto e que sejam contra o discurso da "pacificação". No entanto, ao mesmo tempo em que a mídia muda seu viés discursivo, ela mantém a mesma lógica superficial para tratar do tema, como se o problema da violência e do tráfico de drogas ilegais estivesse sendo resolvido.

Além do problema da violência, não há reflexão nenhuma na mídia hegemônica em relação às favelas pacificadas, e a escolha das favelas para implementação das UPPs estarem próximas ao entorno dos locais onde serão realizadas provas dos Jogos Olímpicos e da Copa do Mundo e das principais vias de acesso à cidade. Há claramente uma preocupação com 
pontos específicos do Rio de Janeiro, e não com a construção de uma política pública para a cidade como um todo.

Nossa hipótese é que os meios de comunicação hegemônicos, enquanto intelectuais orgânicos das classes mais abastadas, justificam formas específicas de gestão estatal dos territórios populares do Rio de Janeiro e representam a favela como um outro, um território e uma forma de vida que não teria lugar no conjunto da cidade. Esse posicionamento naturaliza essa visão de mundo não apenas para os não moradores dos espaços populares, mas também para eles - os próprios moradores - que vivem à margem da cidade enquanto território da violência e de uma sociabilidade avessa às normas e valores hegemônicos.

Mesmo com a nova postura do Estado e da mídia de trabalhar com a ideia de pacificação, percebemos a continuidade do tratamento historicamente diferenciado em relação às favelas e espaços populares e, consequentemente, de seus moradores. Eles continuam sem voz e sem direitos.

\section{A IDEOLOGIA DA MÍDIA}

Maquiavel (1996), na obra O príncipe, dois conceitos centrais: são os sentidos de utilidade - de que o virtuoso é o que é útil - e o de habilidade política - a capacidade de decisão, que poucos personagens históricos teriam. Maquiavel aponta que através da habilidade política (virtude) o governante consegue obter sucesso e a manutenção do poder. A virtude seria a astúcia política, a destreza do governante em obter sucesso. Diferente do que era propagado em sua época, Maquiavel (1996) demonstra que o poder e a dominação não dependiam do destino, mas da forma de se governar:

Deveis, portanto, saber que há dois meios de combate: um com as leis, outro com a força: o primeiro é próprio do homem, o segundo, das bestas; mas, como o primeiro muitas vezes não basta, convém recorrer ao segundo. Portanto, a um príncipe é necessário saber usar bem a besta e o homem (MAQUIAVEL, 1996, p. 131).

Além da lei e da força (ou coerção), o pensador italiano Antonio Gramsci aponta o conceito de hegemonia como algo que opera não apenas sobre a estrutura econômica e sobre a organização política da sociedade, mas também sobre o modo de pensar, sobre as orientações ideológicas. Para ele, a manutenção das estruturas de dominação não se dá apenas pela coerção, mas principalmente pela sua capacidade de mistificar as relações sociais existentes. A hegemonia seria então a capacidade de direção política, cultural e ideológica. Ou seja, para 
além da coerção e da imposição, a hegemonia resulta numa liderança moral e intelectual que uma classe ou fração de classe exerce sobre o conjunto da sociedade, a partir da difusão de seus valores, de sua visão de mundo.

Nossa busca aqui é entender as formas pelas quais as ideias desses grupos e classes dominantes mantem essas relações de dominação. Kellner (2001) aponta que

numa cultura da imagem dos meios de comunicação de massa, são as representações que ajudam a constituir a visão de mundo do indivíduo (...) consumando estilos e modos de vida, bem como pensamentos e ações sociopolíticas. A ideologia é, pois, tanto um processo de representação, figuração, imagem e retórica quanto um processo de discursos e ideias. Além disso, é por meio do estabelecimento de um conjunto de representações que se fixa uma ideologia política hegemônica (KELLNER, 2001, p. 82).

Nesse sentido, a hegemonia também "faz parte de um sistema de dominação que serve para aumentar a opressão ao legitimar forças e instituições que reprimem e oprimem” (idem, p. 84). Essa legitimação se daria a partir da construção de hegemonia, tomando em conta a contribuição de Gramsci para este conceito. Para ele, a hegemonia não se limita à coerção física e econômica, mas se dá também através da busca pelo consenso de uma classe ou bloco de classes sobre as outras (1999). Assim, temos a mídia como uma ferramenta de forte influência nessa mediação de forças entre blocos e classes. Dênis de Moraes (2009) explica a partir do conceito de Gramsci - que a hegemonia é

obtida e consolidada em embates sociais que não comportam apenas as questões vinculadas à estrutura econômica (ainda que esta interfira na organização e na transmissão dos valores culturais) e a organização política; englobam também visões de mundo que ambicionam conquistar consentimento a saberes, práticas, modelos de representação e concepções de autoridade e poder. As disputas por posições incluem assim o plano éticocultural, as orientações ideológicas que querem legitimar-se socialmente e universalizar-se (MORAES, 2009, p. 35).

A partir dessas postulações, retornamos às formas como as favelas e periferias do Rio de Janeiro foram retratadas pela mídia hegemônica ao longo do século XX e em especial a partir da década de 1980: como territórios inimigos em uma guerra entre o bem o mal. A lógica de cidade partida era cada vez mais difundida. Os discursos dos agentes públicos baseavam-se numa estratégia que legitimava uma política de segurança baseada no confronto. É apenas a partir do final de 2008, com a implantação da primeira Unidade de Polícia Pacificadora (UPP) na cidade do Rio de Janeiro, que o discurso de "pacificação" sobrepõe-se ao de "guerra". Esse novo imaginário se torna coletivo a partir da influência decisiva da mídia hegemônica. Essa influência se dá através do que Muniz Sodré chama de bios midiático. 
Sodré explica que esse novo bios faz com que o homem passe a usar a mídia para dar sustentação à cultura. Com isso, a mídia se torna um instrumento de direcionamento ou de criação de subjetividades. Ou seja, a comunicação e a mídia hegemônica têm a capacidade - e a utiliza - na construção de subjetividades que atendam a demandas de consumo, através de estratégias de produção de necessidades não espontâneas e que acabam pautadas essencialmente pelas novas exigências do mercado de consumo. A mídia hoje "ilumina" determinados temas, deixando de fora partes importantes porque não se adequam aos interesses do jogo de aparências sociais e ao mercado (SODRÉ, 2006b).

Além disso, como explica Sodré, há uma diferenciação proposital na linguagem para determinados tratamentos: "uma prática linguística comum, por parte dos dirigentes, é trocar a palavra violência por força, quando se querem nomear atos de coerção socialmente legitimados" (SODRÉ, 2006b, p. 37). Por exemplo, a polícia usa a "força" contra manifestantes, enquanto manifestantes usam da "violência" contra a polícia: "De acordo com as circunstâncias, você vai atribuir significados negativos ou positivos" (SODRÉ, 2006b).

A mídia hegemônica tem consciência de seu potencial dialógico e de sua influência na sociedade. Não à toa, aponta Chauí (2007, que o dominante se reveste de generalidade e de universalidade que anulam e ocultam a realidade das classes:

a ideologia realiza uma operação bastante precisa: ela oferece à sociedade fundada na divisão e na contradição interna uma imagem capaz de anular a existência efetiva da luta, da divisão e da contradição: constrói uma imagem da sociedade como idêntica, homogênea e harmoniosa. Fornece aos sujeitos uma resposta ao desejo metafísico de identidade e ao temor metafísico da desagregação (CHAUÍ, 2007, p. 38).

Para que a violência da dominação exercida por uma classe seja considerada como natural e legítima, sem insuflar uma revolta nos dominados, é preciso que essa dominação seja anulada como violência. Para isso, produz-se uma imagem unificada da sociedade, com indicadores suportáveis e aceitáveis para todos os seus membros. A ideia de que o Estado representa toda a sociedade e que todos os cidadãos estão representados pelo Estado e que todos têm direito à cidadania, é a forma de legitimar a dominação. Chaú́ (2007) diz que essa operação ideológica passa por dois ocultamentos: “o da divisão social e o do exercício do poder por uma classe social sobre outra" (CHAUÍ, 2007, p. 39).

Entendemos aqui que a ideia de pacificação difundida pelo Estado e pelas mídias hegemônicas é uma forma de vincular a sensação de que todos os cidadãos têm direito à cidadania. Como resume Dênis de Moraes, o sistema midiático possui três características 
principais: 1) a capacidade de fixar sentidos e ideologias, interferindo na formação da opinião pública e no imaginário social; 2) apropriação de diferentes léxicos para tentar colocar dentro de si todos os léxicos, a serviço de suas conveniências particulares e; 3 ) incute e celebra a vida para o mercado, a supremacia dos apelos consumistas, o individualismo e a competição, apresentando o mercado como capaz de traduzir os anseios da sociedade. Ou seja, sempre operam consensualmente para reproduzir a ordem do consumo e conservar hegemonias constituídas (2013, p. 20-1). Para Moraes, o sistema midiático "não apenas legitima o ideário global, como também o transforma no discurso social hegemônico, propagando valores e modos de vida que transferem para o mercado a regulação das demandas coletivas" (idem, p. 46)

É nesse sentido que Ianni (1999) faz uma análise da mídia a partir das ideias de Maquiavel e Gramsci. Para ele, a mídia é o novo príncipe, o "príncipe eletrônico", que não seria o condottiero de Maquiavel, nem o partido político (o moderno príncipe cunhado por Gramsci), mas

realiza e ultrapassa os descortinos e as atividades dessas duas figuras clássicas da política. O príncipe eletrônico é uma entidade nebulosa e ativa, presente e invisível, predominante e ubíqua, permeando continuamente todos os níveis da sociedade, nos âmbitos local, nacional, regional e mundial. É o intelectual orgânico das estruturas e blocos de poder presentes, predominantes e atuantes em escala nacional, regional e mundial, sempre em conformidade com os diferentes contextos socioculturais e políticoeconômicos desenhados no novo mapa do mundo (IANNI, 1999, p. 14).

Podemos entender o príncipe eletrônico, ou a mídia hegemônica, como o intelectual orgânico dos grupos, classes ou blocos de poder dominantes. Em alguma medida, como aponta Ianni, "esses grupos, classes ou blocos de poder dispõem de influência mais ou menos decisiva nos meios de comunicação, informação e propaganda, isto é, na mídia eletrônica e impressa, sempre funcionando também como indústria cultural” (IANNI, 1999).

A mídia então exerce o papel da hegemonia, ou seja, tem a capacidade de unificar através da ideologia e de conservar unido um bloco social marcado por profundas contradições de classe. Como aponta Gruppi (1978),

uma classe é hegemônica, dirigente e dominante, até o momento em que através de sua ação política, ideológica, cultural - consegue manter articulado um grupo de forças heterogêneas, consegue impedir que o contraste existente entre tais forças exploda, provocando assim uma crise na ideologia dominante, que leve à recusa de tal ideologia, fato que irá coincidir com a crise política das forças no poder (GRUPPI, 1978, p. 70). 


\section{UM NOVO CONSENSO}

$\mathrm{Na}$ perspectiva de demonstrar empiricamente a alteração da visão de mundo apresentada pela mídia em relação à política de segurança pública carioca, apresentamos na sequência trechos de editoriais, matérias e reportagens veiculadas pelo jornal O Globo. Nosso objetivo é demonstrar nossa hipótese de que houve uma significativa mudança na postura da mídia, que até então apoiava a lógica do confronto como única alternativa para a segurança, e que quase instantaneamente altera seu discurso passando a apoiar uma outra lógica, que vai na contramão das ideias antes difundidas.

Em 20 de outubro de 2007, logo após a realização dos jogos Pan-americanos do Rio e antes da instalação das Unidades de Polícia Pacificadora (UPP), o jornal O Globo escrevia em seu editorial:

\section{Ação e reação}

Não se deve entender como um princípio geral da polícia a formulação do secretário de Segurança do Rio, José Mariano Beltrame, de que não há como enfrentar o crime organizado com ações leves. Mas, no atual estágio de contaminação do organismo social pela violência advinda do poder de fogo das quadrilhas que dominam o tráfico de drogas no estado, não há outro preceito que possa fundamentar a atuação dos policiais.

Sob esse aspecto, tem sido correta, em sua essência, a política adotada pelos organismos policiais fluminenses, a partir da recente operação no Complexo do Alemão, de recorrer a intervenções pontuais nas zonas de guerra, dominadas pelos traficantes à base de terror, assassinatos e perseguições.

(...)

A outra ponta dessa política é exatamente a maneira como os policiais enfrentam os bandidos. Não se trata de fazer apologia da violência, mas o Rio vive uma situação de fato: há nesses nichos à margem da lei criminosos providos de armas e desprovidos de qualquer noção de apreço à vida humana.

A defesa da sociedade pressupõe o combate ao tráfico, com ações afirmativas para fazer frente ao atual quadro de urgência. É certamente a essa necessidade emergencial que o secretário Beltrame se refere quando dá o tom de como deve ser a reação policial nas operações em curso.

Se há uma alternativa que não implique responder a essa situação de guerra com a força do braço armado do Estado, que seja apresentada pelas entidades que têm criticado a atuação da polícia. Seria de fato preferível substituir as armas pela sociologia, mas pelo menos neste caso a receita desanda: faltaria combinar com os bandidos (O GLOBO, 2007, p. 6).

A operação no conjunto de favelas do Alemão que o jornal faz referência aconteceu no dia 27 de junho de 2007, quando 1350 homens, entre policiais civis, militares e da Força de Segurança Nacional invadiram o Complexo do Alemão. Nesta "megaoperação", como foi intitulada pelas forças de segurança, 19 pessoas foram mortas, muitas com indícios de execução. Por conta das denúncias de execuções na megaoperação no Alemão, a Secretaria 
Especial de Direitos Humanos na Presidência da República (SEDH) produziu um Relatório Técnico, onde indica que houve realmente execuções sumárias entre os 19 mortos. De acordo com o parecer da SEDH a análise dos laudos cadavéricos traz evidências de execuções:

A análise da topografia dos orifícios de entrada dos projéteis de arma de fogo evidencia maior concentração em regiões letais. Do total de mais de setenta orifícios de entrada, cinquenta e quatro atingiram regiões mortais, o que correspondem a cerca de $75 \%$ (SEDH, 2007).

Um segundo relatório, elaborado pelo relator da Organização das Nações Unidas (ONU) para Execuções Sumárias, Arbitrárias e Extrajudiciais, Philip Alston, apresentado no dia 2 de junho de 2008 em Genebra, durante o Conselho de Direitos Humanos da ONU, enfatizava sua preocupação com as "megaoperações" realizadas nas favelas do Rio. Para ele, “apesar da operação, realizada em junho de 2007 (...) ter resultado em 19 mortes, autoridades do governo do estado declaram ser esta operação um modelo para as ações futuras da polícia" (apud JUSTIÇA GLOBAL, 2008, p. 9). Alston também questiona os resultados dessa política de segurança e da megaoperação, por não alcançarem resultados significativos:

Os mais importantes traficantes não foram presos ou mortos, e poucas drogas e armas foram apreendidas. Nenhum policial foi assassinado e poucos foram feridos, mas a "resistência" encontrada justificaria, aparentemente, o assassinato de 19 indivíduos (JUSTIÇA GLOBAL, 2008, p. 11).

Era esse tipo de operação policial que o jornal O Globo fazia referência elogiosa em seu editorial.

Pouco mais de um ano depois deste editorial seria instalada, no dia 19 de dezembro de 2008, a primeira Unidade de Polícia Pacificadora (UPP) no Morro Santa Marta, em Botafogo, zona sul da capital. Desde então passam a serem recorrentes matérias e reportagens exaltando a "nova" política de segurança junto às favelas. Já no dia 21 de fevereiro de 2009, O Globo apresenta a seguinte reportagem: "O elogio das UPPs: pesquisa mostra que 93\% dos moradores aprovam unidades, mas 68\% temem volta do tráfico"; em maio, a comandante Pricilla de Oliveira, da UPP do Santa Marta é entrevistada por Mauro Ventura, na coluna "Dois cafés e a conta", na Revista da edição do domingo dia 10 de maio de 2009. As matérias elogiosas não cessam. Em edição no final de 2009, com a retrospectiva do ano, o jornal publica a seguinte matéria:

A redenção das favelas: Com UPPs, Estado resgatou seu papel em áreas há décadas dominadas pelo tráfico

Uma Zona Sul em paz é o presente que todos os cariocas gostariam de ganhar, mas, há pouco mais de um ano, isso não passava de um sonho. Nem os mais otimistas poderiam imaginar que 2009 entraria para a história da cidade fazendo toda a diferença numa guerra contra o tráfico, que se arrasta 
há décadas. Depois de a política ter subido o morro e instalado uma Unidade de Polícia Pacificadora (UPP) no ponto mais alto do Dona Marta, em Botafogo, pouco antes de o ano começar, o Estado chegou a outras favelas, como Babilônia e Chapéu Mangueira, no Leme; Pavão-Pavãozinho e Cantagalo, em Copacabana e Ipanema; e, ainda por ali, Cabritos e Ladeira dos Tabajaras. Os dois morros, cuja ocupação chegou a ser adiada por causa do Natal, foram ocupados, sem um único disparo, no fim de semana passado, pela tropa de elite da PM, e já fazem parte de um corredor na orla que está completamente "dominado". Pela polícia (O GLOBO, CADERNO ESPECIAL, 2009, p. 3).

Em 07 de julho de 2013, o mesmo jornal O Globo que havia apoiado abertamente a política de confronto, estamparia em suas páginas o seguinte editorial:

UPP é patrimônio da sociedade

(...) E como a política de segurança bancada por ele [Erir Ribeiro, destituído do cargo] e executada com eficiência por Beltrame é ponto forte de sua gestão [do governador Sérgio Cabral], ela se torna alvo de toda sorte de aspirante ao poder nas urnas do ano que vem. Cabe, então - como fez o próprio Cabral —, reafirmar a continuidade da política. Não porque ele queira, mas devido ao seu êxito, reconhecido dentro e fora do Rio de Janeiro. Chamado de UPP, mas, na realidade, algo além da pacificação, este programa de segurança pública, hoje com 33 unidades instaladas, tem provocado mudanças para melhor principalmente nas Zonas Sul, Norte e Centro nunca observadas.

(...) A recuperação do controle de áreas pelo estado e o banimento de armas pesadas de favelas têm revitalizado bairros, como a Tijuca. O patrimônio de centenas de milhares de pessoas volta a se valorizar, e 500 mil moradores das chamadas comunidades já estão livres da ditadura do tráfico. Caem as mortes, reduzem-se gastos na Saúde e os dramas familiares.

A política de segurança está para o Rio de Janeiro como o controle da inflação para o país: é inegociável. Tem de ser preservada por todos, em especial políticos com espírito público. Investir contra ela é ajudar a criminalidade. Inclusive a que se infiltra nas polícias (O GLOBO, 2013).

Outras matérias podem servir de exemplo, sempre com a mesma perspectiva. Por exemplo, em matéria de 2013:

Mais vidas nos morros pacificados

Para aliviar o calor, meninos tomam banho de mangueira (...). Alheios à algazarra, moradores e turistas circulam entre vielas (...). Anos atrás, a imagem seria diferente. No local onde os garotos hoje se banham havia um ponto de venda de drogas, traficantes ditavam as regras, e a lei era a do fuzil. Com a implantação da primeira Unidade de Polícia Pacificadora (UPP) do Rio, a comunidade de seis mil habitantes, em Botafogo, viu a rotina de guerra mudar e há cinco anos não conta um assassinato. (O GLOBO, 2013, p. 36)

A mudança de discurso em relação à política de segurança, da não pregação do confronto armado, como já apontado, se dá justamente quando o Rio de Janeiro se torna cidade sede das Olimpíadas de 2016 e cidade-sede da Copa das Confederações e Copa do 
Mundo de Futebol. Momento que ocasiona uma enxurrada de investimentos na cidade. Uma relação possível de diagnosticar em relação às UPPs e os investimentos imobiliários também podem ser vistos nos jornais. No domingo seguinte à instalação da UPP no Santa Marta, a edição do jornal O Globo de 21 de dezembro estampa em sua capa a manchete:

\section{Esperança e medo no Santa Marta}

Há um mês, desde que teve início a ocupação policial, o Morro Dona Marta, em Botafogo, vive uma espécie de vida nova. Com o tráfico fora de cena, a favela experimenta um período de tranquilidade e até a procura por apartamentos na vizinhança aumentou em pelo menos $25 \%$, contendo, segundo corretores, o processo de desvalorização imobiliária, que era crescente (O GLOBO, 2008, p. 1).

No mapa abaixo (Figura 1), encontrado no livro "SMH 2016: Remoções no Rio de Janeiro Olímpico" verificamos claramente ondem estão instaladas as Unidades de Polícia Pacificadora, e onde foram realizados os jogos da Copa do Mundo e onde serão os das Olimpíadas. Nele observamos uma forte incidência das UPPs justamente onde serão realizadas as atividades esportivas desses megaeventos.

Figura 1 - Unidades de Polícia Pacificadora no Rio de Janeiro 2014

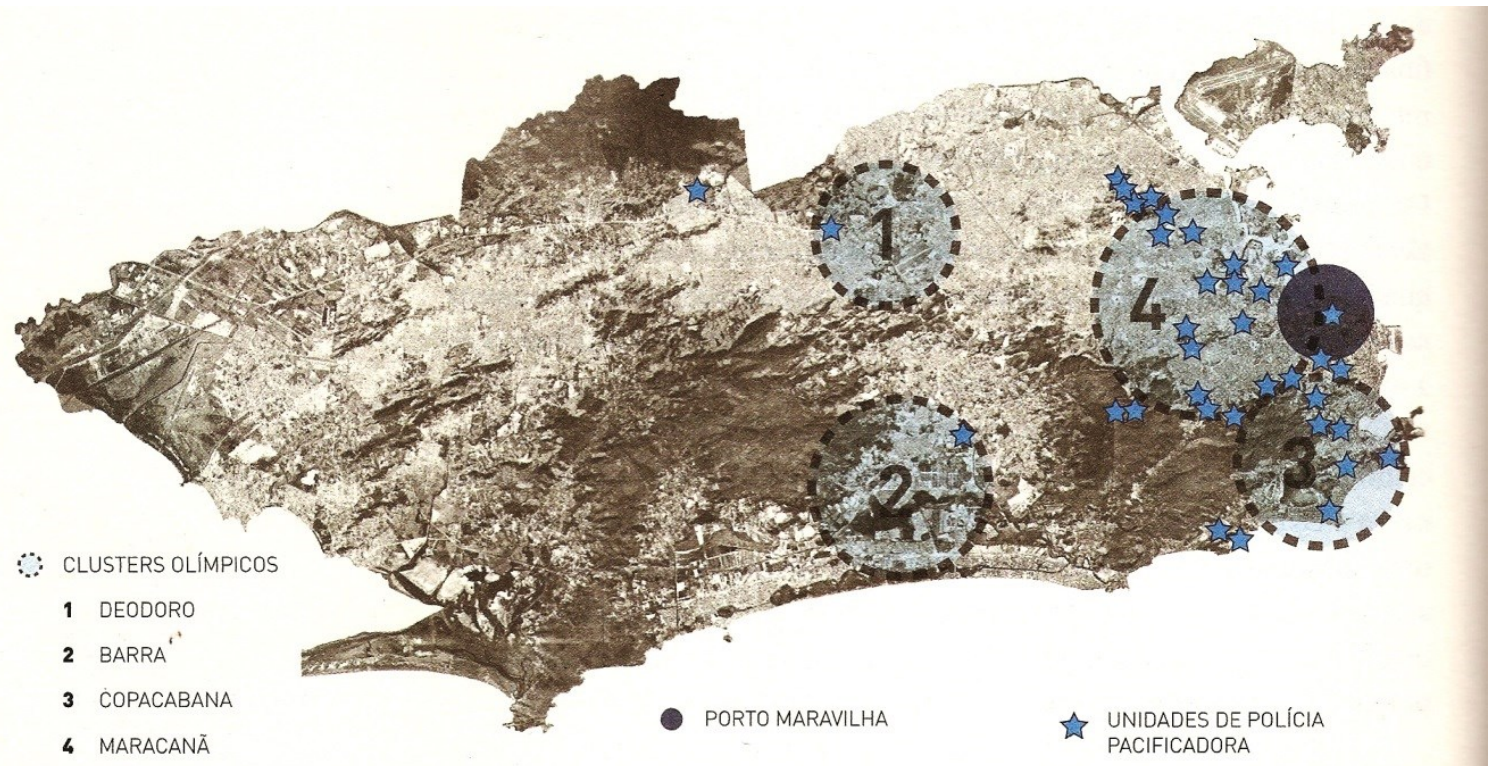

Fonte: Secretaria de Segurança Pública do Rio de Janeiro / Gerência de Terras e Reassentamentos da SMH (abril de 2012)

\section{CONSIDERAÇÕES FINAIS}

A partir das reflexões apresentadas, podemos concluir que a mídia hegemônica atual como um intelectual orgânico das classes, blocos e grupos de poder dominantes. Enquanto havia interesse em disseminar uma lógica de confronto, de guerra às drogas, que justificasse 
os conflitos e a morte de traficantes e moradores de favelas, esse discurso era difundido. A partir do momento que o mercado encontra uma nova necessidade, de uma imagem de cidade mais pacífica, sem conflito, aberta para investimentos por conta dos megaeventos, a mídia incorpora um novo discurso, mesmo que o cerne da política de segurança não tenha se alterado. Mesmo a partir da "pacificação" nas favelas, o valor da vida continua sendo geograficamente hierarquizado. Um tiro ou morte em uma área nobre da cidade continua tendo mais repercussão do que na favela ou outro espaço popular. Em declaração recente do secretário de Segurança Pública José Mariano Beltrame, no mesmo dia em que uma criança de 12 anos, e um jovem de 22 anos foram assassinados por policiais no Morro do Dendê, na Ilha do Governador, um médico foi morto a facadas na Lagoa Rodrigo de Freitas. A repercussão da morte do médico foi mais difundida, mas o mais grave talvez tenha sido o depoimento que o secretário gravou em vídeo e disponibilizou via assessoria de imprensa. Nela ele não faz qualquer menção às mortes na favela e diz que:

É inadmissível o que aconteceu ontem na Lagoa Rodrigo de Freitas, um lugar querido por todos os cariocas, um lugar frequentado pela população do Rio de Janeiro e pela população estrangeira, e por todos os turistas que vêm ao Rio de Janeiro. (...) Um lugar como a Lagoa Rodrigo de Freitas não pode, de maneira nenhuma, ser alvo desse tipo de atitude, porque é um local onde todos nós frequentamos, onde todos nós gostamos de ir, gostamos de frequentar, é um cartão postal, e nós não podemos admitir de maneira nenhuma que ações dessa natureza aconteçam. Muito embora a gente entenda as dificuldades que as polícias têm de trabalhar, mas ações dessa natureza, nesse local, é inadmissível (...) e o atual comando assume com esta primeira missão que é a proteção total da Lagoa Rodrigo de Freitas (grifo nosso) $(\mathrm{G} 1,2015)$.

Ou seja, a relação da mídia hegemônica com as favelas cariocas tem historicamente buscado dar destaque aos interesses dos grupos e classes que sustentam essa mídia. Daí também a influência desses grupos e classes sobre seu conteúdo. Ianni (1999) aponta que o que singulariza a mídia é que ela

realiza limpidamente a metamorfose da mercadoria em ideologia, do mercado em democracia, do consumismo em cidadania. Realiza limpidamente as principais implicações da indústria cultural, combinando a produção e a reprodução cultural com a produção e reprodução do capital; e operando decisivamente na formação de "mentes" e "corações", em escala global (IANNI, 1999, p. 17).

A mídia hegemônica - ou príncipe eletrônico como denomina Ianni (1999) -, atua na elaboração e difusão das concepções de mundo, atuando a favor dos grupos e blocos de poder dominantes. A mídia é uma figura que "influencia, subordina, transforma ou mesmo apaga partidos políticos, sindicatos, movimentos sociais, correntes de opinião, legislativo, executivo 
e judiciário. (...) Predomina em todas as esferas da política, adquirindo diferentes figurações” (IANNI, 199, p. 24).

Ao falar sobre o "mito", Barthes (1972) o define como uma "fala escolhida pela história" (BARTHES, 1972, p. 132) e que ele tem como função deformar, não fazer desaparecer. O "mito" seria a ferramenta utilizada pela mídia para transmitir sua mensagem, para escrever a história oficial. Ele deforma, mas não elimina o sentido. Ele aponta ainda que existe um termo que significa exatamente esta contradição: alienação (BARTHES, 1972, p. 143-4). O que se espera do mito, explica Barthes, é que ele seja "imediatamente perceptível: o que se espera dele é um efeito imediato: pouco importa se em seguida o mito é desmontado, presume-se que a sua ação é mais forte do que as explicações racionais que podem pouco depois desmenti-lo" (BARTHES, 1972, p. 151). Uma manchete de jornal, por exemplo, tem muito mais impacto - e um impacto muito mais imediato - do que toda a reportagem posterior em letras menores. Ele continua dizendo que a função do mito é transformar uma intenção histórica em natureza, uma contingência em eternidade (idem, p. 162-3). Dessa forma,

passando da história à natureza, o mito faz uma economia: abole a complexidade dos atos humanos, confere-lhes a simplicidade das essências, suprime toda e qualquer dialética, qualquer elevação para lá do visível imediato, organiza um mundo sem contradições, porque sem profundeza, um mundo plano que se ostenta em sua evidência, cria uma clareza feliz: as coisas parecem significar sozinhas, por elas próprias (BARTHES, 1972, p.163-4)

No entanto, a ideologia é um conjunto de ideias no qual grupos sociais - dominantes ou não - postulam, explicam e justificam os fins e os meios da ação política, seja com o objetivo de preservar, corrigir, eliminar ou reconstruir uma ordem social. Assim como as classes, grupos e blocos de poder dominantes lutam pela legitimação e manutenção das estruturas sociais, as classes e grupos subalternos têm o objetivo de questionar e propor alternativas. No mesmo sentido, explica Ianni (1999), o príncipe eletrônico não é também homogêneo ou monolítico:

Além da competição evidente ou implícita entre os meios de comunicação de massas, ocorrem frequentes irrupções de fatos, situações, relatos, análises, interpretações e fabulações que pluralizam e democratizam a mídia. Sem esquecer que são inúmeros os intelectuais de todos os tipos, jornalistas, fotógrafos, cineastas, programadores (...) que diversificam, pluralizam, enriquecem e democratizam a mídia. Há jornais e visões alternativas do que vai pelo mundo (...). Assim se enriquece o príncipe eletrônico, tornando-o mais sensível ao que vai pelo mundo, desde a perspectiva das classes e 
grupos sociais subalternos à perspectiva das classes e grupos sociais predominantes (IANNI, 1999, p. 15).

Esse é um ponto de esperança, de que é possível questionar e lutar por mudanças, de que onde há conformismo, também pode haver resistência. Mas em geral, o que vemos é que o príncipe eletrônico expressa sobretudo a visão de mundo dos blocos de poder predominantes.

\section{REFERÊNCIAS}

5X PACIFICAÇÃO. Produção de Renata Almeida Magalhães e Carlos Diegues. Direção de Cadu Barcellos, Luciano Vidigal, Rodrigo Felha, Wagner Novais. Rio de Janeiro, Brasil, 2012. (86min.). Disponível em:<https://www.youtube.com/watch?v=1QGAjDUtozY>. Acesso em: 02 out. 2015.

ANISTIA INTERNACIONAL. Brasil: o governo deve trabalhar com as comunidades para resolver a crise de segurança. 2007. Disponível em: $<$

https://www.amnesty.org/download/Documents/60000/amr190152007pt.pdf>. Acesso em: set. 2013.

ARAÚJO, V. Ação no Dona Marta aquece mercado imobiliário. O Globo, Rio de Janeiro, p. 16-17, 2008.

ARAÚJO, V. O rastro de segurança da UPP. O Globo, Rio de Janeiro, p. 16, 2009.

BARTHES, R. Mitologias. São Paulo: Difusão Europeia do Livro, 1972.

BOTTARI, E.; ARAÚJO, V. O elogio das UPPs. O Globo, Rio de Janeiro, p. 14, 2010,

CHAUÍ, M. Cultura e democracia: o discurso competente e outras falas. 12. ed. São Paulo: Cortez, 2007.

COIMBRA, C. Operação Rio: o mito das classes perigosas: um estudo sobre a violência urbana, a mídia impressa e os discursos de segurança pública. Rio de Janeiro: Oficina do autor, 2001.

FAULHABER, L.; AZEVEDO, L. SMH 2016: remoções no Rio de Janeiro Olímpico. Rio de Janeiro: Mórula Editorial, 2015.

FREIRE, A. Operação na favela da Coréia deixa policiais desanimados. G1, Rio de Janeiro, 2010. Disponível em: <http://g1.globo.com/Noticias/Rio/0,,MUL152010-5606,00OPERACAO+NA+FAVELA+DA+COREIA+DEIXA+POLICIAIS+DESANIMADOS.html $>$. Acesso em: 13 set. 2013.

CRIME na Lagoa é 'inadmissível', diz Beltrame, que anunciou mudanças. G1, Rio de Janeiro, 2015. Disponível em: <http://g1.globo.com/rio-de-janeiro/noticia/2015/05/crime-na-lagoa-e-inadmissiveldiz-beltrame-que-anunciou-mudancas.html > . Acesso em: 26 maio de 2015.

GRAMSCI, A. Cadernos do cárcere. Rio de Janeiro: Civilização Brasileira, 2007. 3v

IANNI, O. O príncipe eletrônico. Perspectivas, São Paulo, n. 22, p. 11-29, 1999. 
RIO DE JANEIRO (Estado). Instituto de Segurança Pública do Estado do Rio de Janeiro. Balanço de incidências criminais e administrativas no estado do Rio de Janeiro, Rio de Janeiro, RJ, 2008. 1. semestre de 2008.

A MÍDIA produziu seus próprios intelectuais. JB On Line, Rio de Janeiro, 2004. Disponível em: $<$ http://www.observatoriodaimprensa.com.br/news/view/bia_barbosa_26908>. Acesso em: 13 set. 2013

RIO DE JANEIRO (Estado). Justiça Global. Relatório Rio: violência policial e insegurança pública. 2004. Disponível em: <http://global.org.br/wp-content/uploads/2012/02/Relat\%C3\%B3rio-Rio$\%$ E2\%80\%93-Viol\%C3\%AAncia-policial-e-Inseguran\%C3\%A7a-p\%C3\%BAblica-2004.pdf>. Acesso em: 24 de ago. 2013.

JUSTIÇA GLOBAL (Org.). Segurança, tráfico e milícias no Rio de Janeiro. Rio de Janeiro: fundação Heinrich Böll, 2008.

KELNNER, D. A cultura da mídia. Bauru, SP: EDUSC, 2001.

MAQUIAVEL, N. O príncipe. Rio de Janeiro: Paz e Terra, 1996.

MENEZES, M. J. Se alguém tiver que morrer, que morra. O Globo, Rio de Janeiro, p. 15, 2003.

MISSE, Michel. A violência como sujeito difuso. In: FEGHALI, J.; MENDES, C.; LEMGRUBER, J. (Orgs.). Reflexões sobre a violência urbana: (in)segurança e (des)esperanças. Rio de Janeiro: Mauad, 2006.

MORAES, D. A batalha da mídia: governos progressistas e política de comunicação na America latina e outros ensaios. Rio de Janeiro: Pão e Rosas, 2009.

MORAES, D; RAMONET, I.; SERRANO, P. Mídia, poder e contrapoder: da concentração monolítica à democratização da informação. São Paulo: Boitempo; Rio de Janeiro: FAPERJ, 2013.

POLICIAL admite ter atirado em pescador e criança no Morro do Dendê. O Dia Rio, Rio de Janeiro, 2015. Disponível em:<http://odia.ig.com.br/noticia/rio-de-janeiro/2015-05-20/policial-admite-teratirado-em-pescador-e-crianca-no-morro-do-dende.html>. Acesso em: 26 maio 2015.

AÇÃO e reação. O GLOBO, Rio de Janeiro, p. 6, 2007.

A NECESSÁRIA reação ao surto de violência. O Globo, Rio de Janeiro, p. 6, 2014.

UPP é patrimônio da sociedade. O Globo, Rio de Janeiro, p. 6, 2013.

OPERAÇÃO na favela da Coréia deixa 12 mortos, entre eles um menino de 4 anos. O Globo On Line, Rio de Janeiro, 2007. Disponível em:< http://oglobo.globo.com/rio/mat/2007/10/17/298182778.asp>. Acesso em: 20 de jan. de 2009.

BELTRAME: 'um tiro em Copacabana é uma coisa. Na Favela da Coréia é outra'. OAB critica diferenciamento. O Globo On Line, Rio de Janeiro, 2007. Disponível em:< http://extra.globo.com/noticias/rio/beltrame-um-tiro-em-copacabana-uma-coisa-na-favela-da-coreiaoutra-oab-critica-diferenciamento-720077.html\#ixzz37dYjIB9g>. Acesso em: 15 jun. 2014.

RAMALHO, S. Paz nas favelas para os jogos. O Globo, Rio de Janeiro, p. 12, 2009. 
ROCHA, C.; ALVES, M. E. A redenção das favelas. O Globo, Rio de Janeiro, p. 331, 2009.

ROCHA, C.; SCHMIDT, S.; RAMALHO, S. Mais vida nos morros pacificados. O Globo, Rio de Janeiro, p. 36, 2013.

RIO DE JANEIRO (Estado). Justiça Global. Relatório da sociedade civil para o relator especial das Nações Unidas para Execuções Sumárias, Arbitrárias e Extrajudiciais. Rio de Janeiro, 2007.

RIO DE JANEIRO (Estado). Secretaria Especial Dos Direitos Humanos. Relatório Técnico: visita de cooperação técnica. Rio de Janeiro: 2007.

SOARES, R. Sem hipocrisia. Revista Veja, Rio de Janeiro, 2007. Disponível em:< http://veja.abril.com.br/311007/entrevista.shtml>. Acesso em: 24 de ago. de 2013.

SODRÉ, M. Violência, mídia e política. In: FEGHALI, J.; MENDES, C.; LEMGRUBER, J. (Orgs.). Reflexões sobre a violência urbana: (in)segurança e (des)esperanças. Rio de Janeiro: Mauad X, 2006.

SODRÉ, M. Sociedade, Mídia e Violência. Porto Alegre: Sulina, 2002.

CRIANÇA e jovem morrem durante operação policial na Ilha do Governador. UOL Notícias, Rio de Janeiro, 2015. Disponível em: $<$ http://noticias.uol.com.br/ultimas-noticias/agenciaestado/2015/05/19/crianca-e-jovem-morrem-durante-operacao-policial-na-ilha-do-governador.htm. Acesso em: 26 maio 2015.

VALADARES, L. P. A invenção da favela: do mito de origem a favela.com. Rio de Janeiro: Editora FGV, 2005.

WAISELFISZ, J. J. Mapa da violência 2011: os jovens do Brasil. São Paulo: Instituto Sangari; Brasília: Ministério da Justiça, 2011. Disponível em:< http://mapadaviolencia.org.br/pdf2011/MapaViolencia2011.pdf>. Acesso em: 24 ago. 2013.

WAISELFISZ, J. J. Mapa da violência 2012: a cor dos homicídios no Brasil. Rio de Janeiro: CEBELA, FLACSO; Brasília: SEPPIR/PR, 2012. Disponível em:< http://mapadaviolencia.org.br/pdf2012/mapa2012_cor.pdf>. Acesso em: 24 ago. 2013. 